\title{
Cutaneous Angiomyolipoma of the Nose
}

\author{
Oluwapelumi O. Olusoga-Peters ${ }^{1}$, Moses Ayodele Akinola ${ }^{1 *}$, Adekunle Moses Adetayo², \\ Taiwo Olufemi Solaja ${ }^{3}$, Olalekan Abisola Ajayi ${ }^{3}$
}

${ }^{1}$ Otorhinolaryngology Unit, Department of Surgery, Ben Carson School of Medicine, Babcock University, Ilishan Remo, Nigeria ${ }^{2}$ Oral and Maxillofacial Surgery Unit, Department of Surgery, Ben Carson School of Medicine, Babcock University, Ilishan Remo, Nigeria

${ }^{3}$ Department of Histopathology, Ben Carson School of Medicine, Babcock University, Ilishan Remo, Nigeria Email: *ayoakinol12@gmail.com

How to cite this paper: Olusoga-Peters, O.O., Akinola, M.A., Adetayo, A.M., Solaja, T.O. and Ajayi, O.A. (2020) Cutaneous Angiomyolipoma of the Nose. Case Reports in Clinical Medicine, 9, 368-375.

https://doi.org/10.4236/crcm.2020.912051

Received: October 20, 2020

Accepted: December 15, 2020

Published: December 18, 2020

Copyright (C) 2020 by author(s) and Scientific Research Publishing Inc. This work is licensed under the Creative Commons Attribution International License (CC BY 4.0).

http://creativecommons.org/licenses/by/4.0/

\begin{abstract}
Angiomyolipomas (AML) are benign mesenchymal tumours. It is commonly seen in the kidney. Extra-renal sites of AML are uncommon though it can occur in any part of the body. Reports of cutaneous AML are rare in the literature. We present a case of an 11-year-old female with a polypoidal swelling on the nose that was noticed a few weeks after birth, which progressively increased in size till it was causing nasal blockage. This cutaneous lesion is different from a renal angiomyolipoma because it lacks features of tuberous sclerosis, non-invasive, absence of epithelioid cells and negative HMB-45 staining. Histopathology shows a mixture of blood vessels, mature adipocytes and smooth muscle. These unique features distinguish this lesion from other possible differentials such as angiomyoma and myolipoma. Histopathology and immunohistochemistry confirm the swelling as angiomyolipoma of the nose. We concluded that histopathology and immunohistochemistry are important diagnostic tools for cutaneous AML irrespective of gender, age of onset and site of lesion.
\end{abstract}

\section{Keywords}

Angiomyolipoma, Mesenchymal Tumours, Tuberous Sclerosis, Angiolipoleiomyoma

\section{Introduction}

Angiomyolipomas (AML) are benign mesenchymal tumours with varying proportions of matured fat cells, thick walled blood vessels and smooth muscle cells [1]. More than 99\% of AML is found in the kidney [2]. Other documented sites are liver, lung, intestine, oral and nasal cavities and sometimes the skin [1]. The 
renal AML has female predilection, invasive; consists of perivascular epithelioid cells and positive HMB-45 Antigen and about one third is associated with tuberous sclerosis [3]. AML was classified in older literature as hamartomatous lesion, a benign tumour comprising cells of origin, but it is also been found to be associated with other diseases such as neurofibromatosis type 1, polycystic kidney disease and Hippel-Lindau syndrome [3].

The extra-renal AML is less common than the renal counterpart. The cutaneous forms of extra-renal are reported to be even much less common than the renal type and are mostly present in acral region of the body [1]. The ear has been reported to be the commonest site of cutaneous AML on the head and neck region followed by eye, lip, glabella, pre-auricular and post-auricular region and less commonly, the nose [4]. There are only 2 reported cases of cutaneous AML of the external nasal pyramid in literature till date (Buyukbabani et al. and Obata et al.) [5] [6]. Cutaneous AML unlike renal type predominantly affects male; is solitary, non-invasive, and negative for human melanoma black (HMB)-45 antibody and is not associated with tuberous sclerosis. They are mostly within 1 - 4 $\mathrm{cm}$ in dimension. Cutaneous AML has been suggested to develop from replacement of degenerated tissue of neglected lesion with fat tissue following repeated trauma [4].

The purpose of this case report is to describe a rare case of large cutaneous AML located on the nose of a female child. This is the first case report of cutaneous AML in Nigeria.

\section{Case Report}

An eleven-year-old female presented about two years ago with an external nasal growth which was noticed about a week after her birth. Swelling gradually increased in size until it was the size of a baseball. There was no history of associated pain or previous trauma to the nose. There was however associated history or recurrent mucus nasal discharge, nasal blockage and snoring due to partial blockage of both nostrils by the growth. Patient was also diagnosed of ventricular septal defect (VSD) in the neonatal period that was repaired only eighteen months ago due to financial reason.

Examination of the mass revealed a well circumscribed mass over the dorsum of the nose hanging over both nostrils, it is non-tender, soft in consistency, mobile, measuring $6 \mathrm{~cm}$ by $6 \mathrm{~cm}$ in dimension and is attached to the over-lining skin (Figure 1), the nasal cavity is clinically normal. There were also no clinical features of tuberous sclerosis and no positive family history. Because the mass was discrete, an excisional biopsy was favored to incisional biopsy. Nevertheless, Computed tomography (CT) was done with the aim of localizing the mass. CT scan revealed an isodense lesion just within the tip of the nose with relatively normal nasal cavity and paranasal sinuses (Figure 2). The mass was subsequently excised under general anesthesia and closure achieved primarily (Figure 3). The surgical specimen was bluish yellow in color multilobulated and firm 
measuring $4 \mathrm{~cm}$ by $2 \mathrm{~cm}$ by $4 \mathrm{~cm}$ (Figure 3 ).

Histopathology revealed a regularly shaped greyish white to brownish soft tissue masses, the largest of which measure $3 \times 2.5 \times 1.5 \mathrm{~cm}$. Hematoxylin/eosin section showed soft tissue partly covered by a thinned-out epithelium. Within the tissue are proliferating small sized vascular channels, some of which are cystically dilated. There are lobules of matured adipocytes within a somewhat fibromuscular stroma (Figure 4). Immunohistochemistry examination showed cytoplasmic immunoreactivity for SMA in the smooth muscle component and negative HMA-45 (Figure 5). Diagnosis of AML was made based on histologic and immunohistochemistry reports. Informed consent was obtained from the parent for this case report.

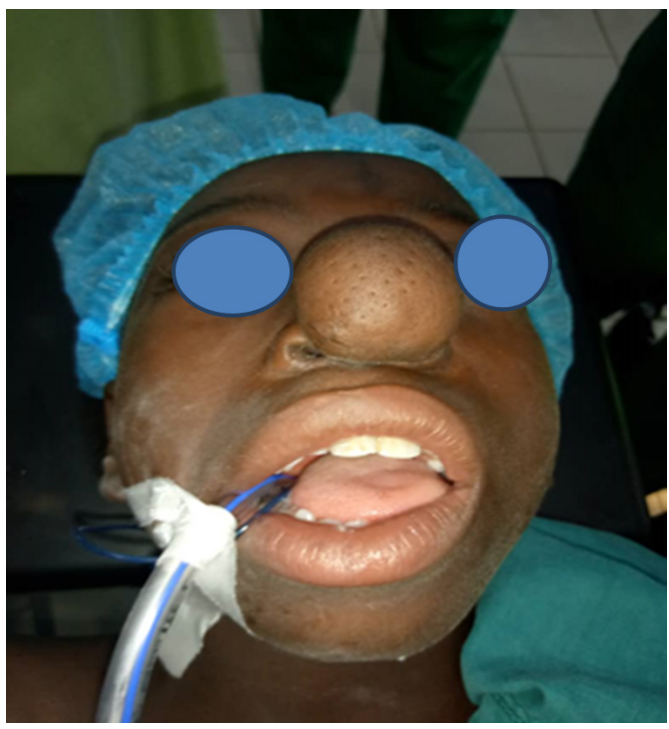

Figure 1. Preoperative picture showing a 6.0 by 6.0 $\mathrm{cm}$ mass on the nasal bridge.
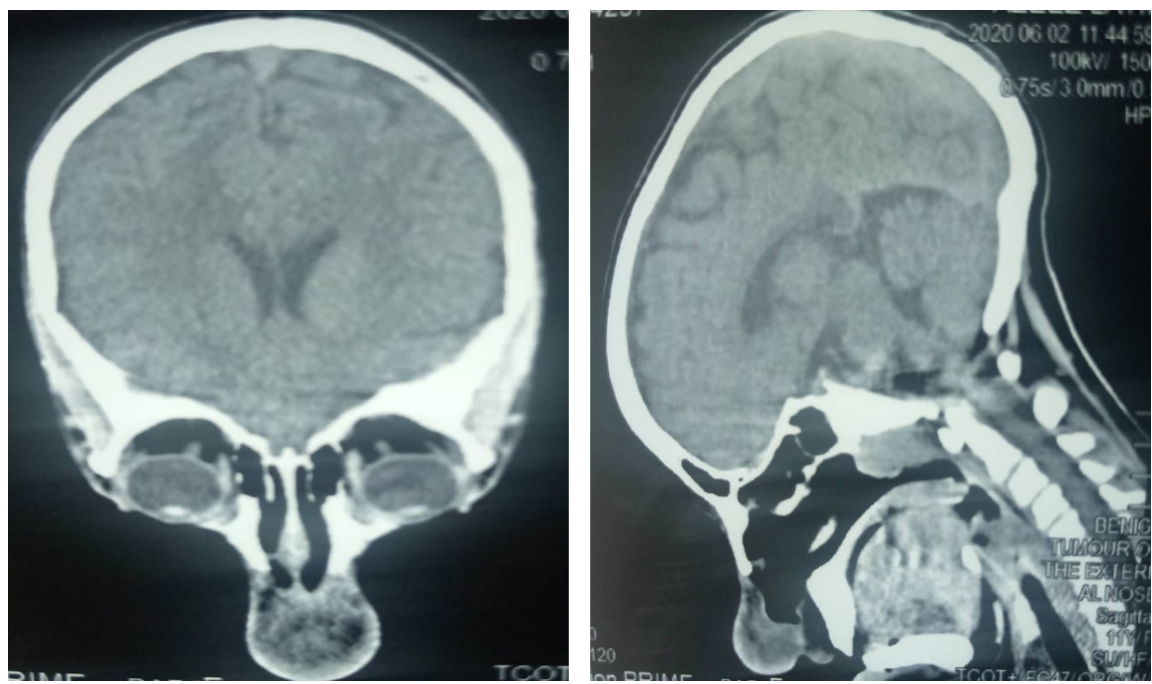

Figure 2. Computed topography scan image showing isodense well circumscribed lesion on the nose. 


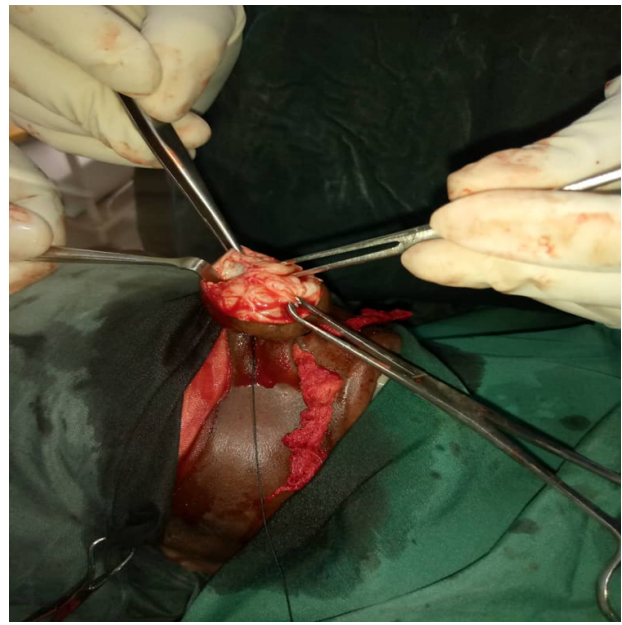

(a)

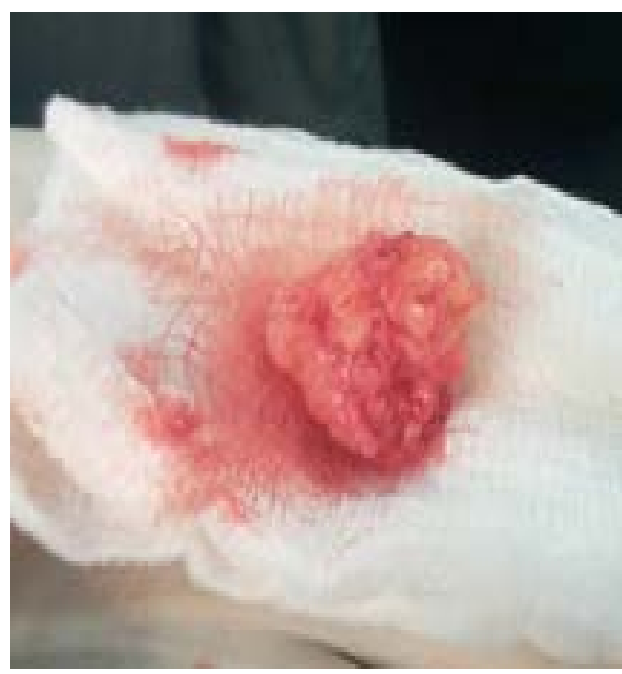

(b)

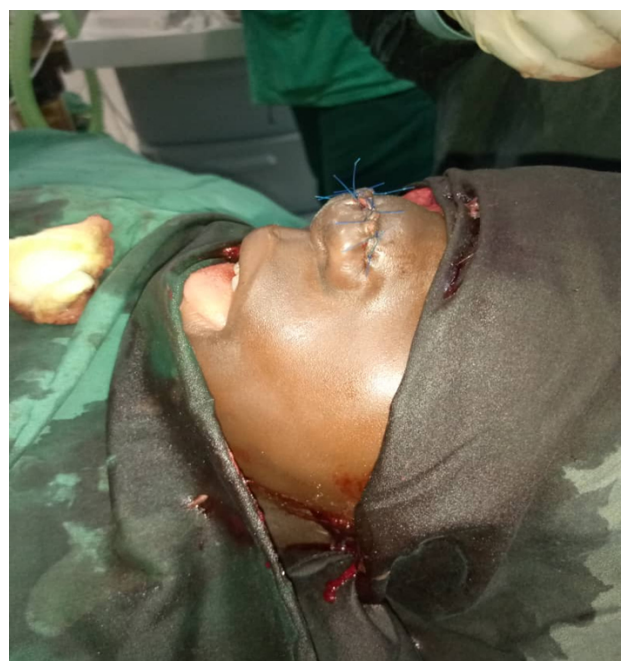

(c)

Figure 3. (a) Intraoperative photograph showing the mass being excised; (b) and (c) showing a $2 \times 4 \mathrm{~cm}$ excised mass and the immediate reconstruction of the nasal bridge respectively. 


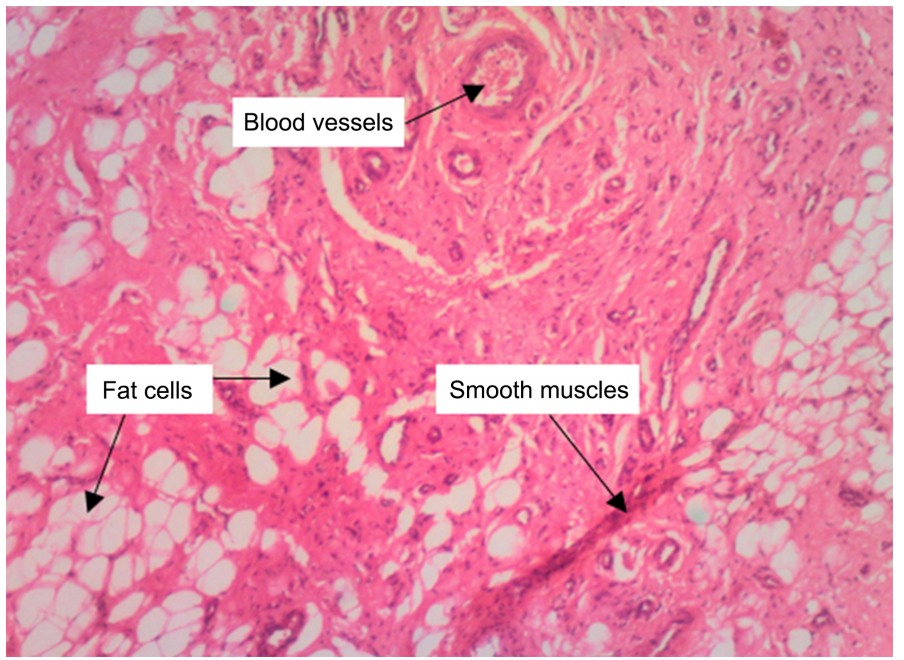

Figure 4. Haematoxylin and eosin staining showing blood vessels, adipose tissue and smooth muscle bundle in varying proportion.

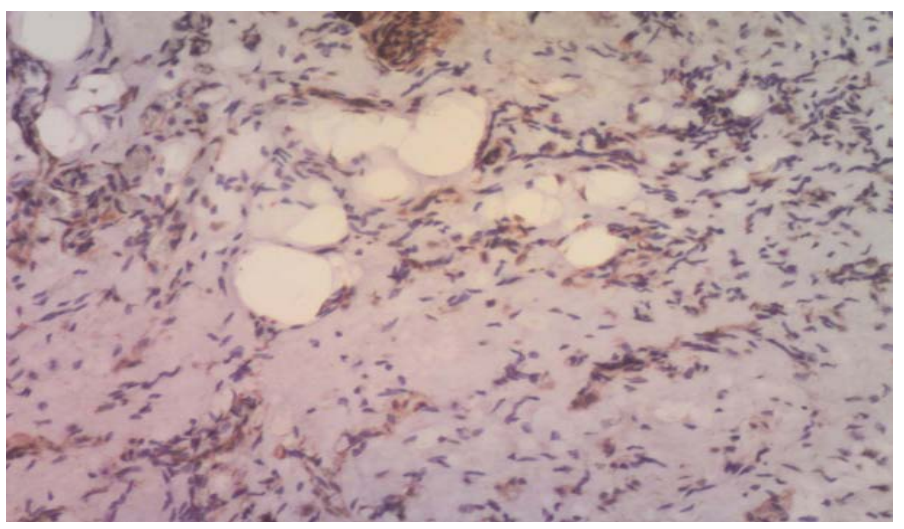

Figure 5. Immunohistochemistry showing sample of the excised tissue being negative for HMB-45 but positive for SMA.

\section{Discussion}

Cutaneous AML an uncommon extra renal form of AML, was first described by Fitzopatrick et al. [7] in 1990 where eight cases of cutaneous AML was reported under the name angiolipoleiomyoma [7]. AML was subsequently classified as hamartomatous tumour which arises from perivascular epithelioid cells [8].

Cutaneous AML has been reported to be commoner in middle aged male population group and rarely seen in children [4]. This in contrast with the patient in this review who is an $11 \mathrm{yr}$ old female that presented with a nasal mass of similar duration as the age. The reason for this could be due to the rarity of AML and its clinic-pathology is only starting to evolved. The size of the lesions in previous case reports were between $1-4 \mathrm{~cm}$ while our case report is $6 \mathrm{~cm}$, presenting as the largest of reported cutaneous AML. This might probably due to the early age of onset of the lesion and the possibility of larger lesion presenting as AML. Clinically cutaneous AML lesions are solitary, asymptomatic, non-invasive and well demarcated [9]. These attributes and its soft nature easily makes it to be 
mis-diagnosed as other commoner lesions like lipoma, fibro-lipoma or mucoid cyst [10] hence, the importance of an histopathological diagnosis. A postoperative histopathology was done in this case to negate the initial impression of a lipoma. This is however similar to what occurred in Shim et al. [10] where an initial mucoid cyst impression was made [10].

Immunohistochemistry is also an important diagnostic tool. The cutaneous AMLs are negative for HMB-45 staining unlike renal types. The patient in this report also showed negative HMB-45 similar to all the reported cutaneous AMLs [3] [6] [7]. Genetic studies could also be done in AML when there are features of tuberous sclerosis, which is known to be associated with renal AML [11]. This was not done for this case as it was not indicated.

AML are histologically diagnosed as benign tumours with classical triad of mature thick-walled blood vessel, smooth muscle and mature adipose tissue in different proportion [12]. AML are also one of the most common benign tumors in the kidney [3], and over 33\% of patients with renal AML are associated with tuberous sclerosis complex (TSC). The patient in this review did not show any features of TSC which includes multiple AMLs, fibrous forehead plague, retinal fibromas or renal AML [2] [11]. A probe into the family history also excludes TSC. This finding is in support of existing report [4] [5] [9], as cutaneous AMLs have not been known to be associated with tuberous sclerosis [4]. There is no sign of recurrence after 3 months follow up similar to most of the reports in the literature [4] (Figure 6).

Literature review on cutaneous AMLs revealed very little knowledge about the entity. However, they are seen as a different disease due to the difference in their clinical features. Nasal cutaneous AML have been rarely reported in literatures, and has only been seen in two cases [5] [6]. These two reported cases are in adult patients with a duration of 3 - 5 years unlike in the case in this review. Delayed diagnosis and management of our case result in recurrent nasal infection and facial disfigurement.

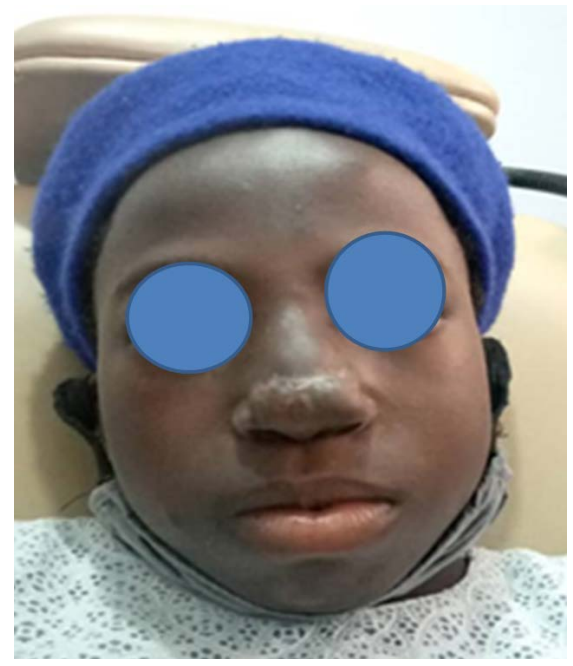

Figure 6. A 3-month post-operative photograph of the patient. 


\section{Conclusion}

We have presented a case of cutaneous AML on the tip of the nose of 11 years old female child, which is the first to be reported in West Africa and the 3rd case of cutaneous AML of the external nasal pyramid to be reported in the literature. The typical findings on histopathology exclude AML from other possible differential diagnosis. There is also no sign of tuberous sclerosis in our case as previously described in literature. Therefore, cutaneous AML should be considered as a differential diagnosis of any cutaneous tumour on the nose from childhood.

\section{Conflicts of Interest}

The authors declare no conflicts of interest regarding the publication of this paper.

\section{References}

[1] Weiss, S.W. and Goldblum, J.R. (2001) Enzinger and Weiss's Soft Tissue Tumors. 4th Edition, Mosby, St. Louis, 605-607.

[2] Fittschen, A., Wendlik, I., Oeztuerk, S., et al. (2014) Prevalence of Sporadic Renal Angiomyolipoma: A Retrospective Analysis of 61,389 In- and Out-Patients. Abdominal Imaging, 39, 1009-1013. https://doi.org/10.1007/s00261-014-0129-6

[3] Argenyi, Z.B., Piette, W.W. and Goeken, J.A. (1991) Cutaneous Angiomyolipoma: A Light-Microscopic, Immunohistochemical, and Electron-Microscopic Study. The American Journal of Dermatopathology, 13, 497-502. https://doi.org/10.1097/00000372-199110000-00012

[4] Shin, J.U., Lee, K.Y. and Roh, M.R. (2009) A Case of a Cutaneous Angiomyolipoma. Annals of Dermatology, 21, 217-220. https://doi.org/10.5021/ad.2009.21.2.217

[5] Buyukbabani, N., Tetikkurt, S. and Ozturk, A.S. (1998) Cutaneous Angiomyolipoma: Report of Two Cases with Emphasis on HMB-45 Utility. Journal of the European Academy of Dermatology and Venereology, 11, 151-154. https://doi.org/10.1111/j.1468-3083.1998.tb00769.x

[6] Obata, C., Murakami, Y., Furue, M. and Kiryu, H. (2001) Cutaneous Angiomyolipoma. Dermatology, 203, 268-270. https://doi.org/10.1159/000051765

[7] Fitzpatrick, J.E., Mellette Jr., J.R., Hwang, R.J., Golitz, L.E., Zaim, M.T., et al. (1990) Cutaneous Angiolipoleiomyoma. Journal of the American Academy of Dermatology, 23, 1093-1098. https://doi.org/10.1016/0190-9622(90)70339-J

[8] Slotweg, P.J. and El-Naggar, A.K. (2018) World Health Organization 4th Edition of Head and Neck Tumor Classification: Insight into the Consequential Modifications. Virchows Arch, 472, 311-313. https://doi.org/10.1007/s00428-018-2320-6

[9] Debloom, J.R., Friedrichs, A., Swick, B.L. and Whitaker, D.C. (2006) Management of Cutaneous Angiomyolipoma and Its Association with Tuberous Sclerosis. The Journal of Dermatology, 33, 783-786. https://doi.org/10.1111/j.1346-8138.2006.00175.x

[10] Shim, H.S., Kim, D.H., Kwon, H. and Jung, S.N. (2014) Cutaneous Angiomyolipo$\mathrm{ma}$ in the Forehead. Journal of Craniofacial Surgery, 25, 1120-1122. https://doi.org/10.1097/01.scs.0000436740.90536.f6

[11] Rakowski, S.K., Winterkorn, E.B., Paul, E., et al. (2006) Renal Manifestations of Tuberous Sclerosis Complex: Incidence, Prognosis, and Predictive Factors. Kidney 
International, 70, 1777-1782. https://doi.org/10.1038/sj.ki.5001853

[12] Kim, H.J., Chan, M.C., Park, J.Y. and Jung, S.G. (2017) Angiomyolipoma of the Glabella Region. Archives of Craniofacial Surgery, 18, 202-206.

https://doi.org/10.7181/acfs.2017.18.3.202 